\title{
THE SIGNIFICANCE OF THE EVALUATION OR ASSESSMENT FACTOR IN THE PEDAGOGICAL EVALUATION PROCESS OF WEB-BASED E- LEARNING
}

\author{
Choolangika Sirisuriya ${ }^{1 *}$, Lochandaka Ranathunga ${ }^{2}$, Shironika Karunanayaka ${ }^{3}$ and \\ Aniza Abdullah ${ }^{4}$ \\ ${ }^{1}$ Department of Computer Science, Faculty of Computing, General Sir John Kotelawala Defence University, Sri \\ Lanka \\ ${ }^{2}$ Department of Information Technology, Faculty of Information Technology, University of Moratuwa, Sri Lanka \\ ${ }^{3}$ Department of Secondary and Tertiary Education, Open University, Sri Lanka \\ ${ }^{4}$ Department of Computer System and Technology, University of Malaya, Malaysia
}

\begin{abstract}
Designing rich learning environments is an important factor in enhancing the success of web-based education. For that reason, the necessity of evaluating web-based e-Learning content is arising. The evaluation process of web-based e-Learning normally includes pedagogical evaluation and subject evaluation because e-Learning course material is a combination of course content, as well as the way it is delivered. Currently, the evaluation process is manually done by pedagogical reviewers who use various evaluation tools comprising of categories of checklists to validate the usability and validity of the e-Learning materials. Inconsistency is considered as one of the most notable challenges identified in the manual pedagogical evaluation process. A calibrated checklist was devised by considering the literature addressing this issue. This checklist was then used to automate the pedagogical evaluation process of web-based e-Learning content. Based on the checklist a questionnaire was produced and a survey conducted with pedagogical experts to identify the most important review factors. The Evaluation or Assessment review factor was highly ranked by the pedagogical reviewers in the survey. Evaluation or Assessment is essential to the learning process in web-based education and is a recognized way of measuring effective learning and assess learner's progress. This study focused on giving comparative clarification about factors considered under Evaluation or Assessment in the manual pedagogical evaluation process of web-based eLearning. This would help to develop a supporting tool to measure the pedagogical effectiveness of Evaluation or Assessment as the main review factor and its sub review factors.
\end{abstract}

Keywords: e-Learning, Evaluation, Assessment, Pedagogical Review

\section{Introduction}

Shifting from traditional learning to electronic learning (e-Learning) is a challenging but yet interesting and promising step for current educational system. e-learning is an approach to facilitate and enhance learning based on both computer and communications technology. Most of the educational institutes including universities have strong potential to shift e-Learning because of the advances in hardware technologies, open source software and communications. Designing e-Learning course materials is an important step toward the success of any e-Learning program. Applying pedagogical concepts and following standards at design time simplifies this challenge. For that reason, the necessity of evaluating web-based e-Learning content is arising.

The evaluation process usually consists of pedagogical evaluation and content evaluation because e-Learning course material is a combination of the course's content as well as the way it is delivered (de S Sirisuriya et al., 2013a). Content reviewing is done by subject matter expert and pedagogical reviewing part of web based eLearning content is done by pedagogical expert. This research study mainly based on pedagogical evaluation 
process of web based e-Learning content. Inconsistency is the biggest challenge faced by pedagogical reviewers as identified based on the study of the manual pedagogical evaluation process. This is evident when different institutes used different set of checklists in order to pedagogically evaluate their web based e-Learning content(de S Sirisuriya et al., 2013b). Based on the literature, a calibrated checklist was design to use in web based e-Learning content evaluating process. When we developing the checklist, we remove similar reviewing factors and consider only the reviewing factors which can be automated. Course Overview and Introduction, Accessibility, Structure of the Course, Learner Interface of the Course, Language, Learning Resources, Interaction and Activities, Evaluation or Assessment, Learner Support, Navigational Structure and the Overall Presentation Outlook were the eleven main review factors considered in this calibrated checklist. Each main review factor was then divided into several sub review factors to give better explanation to pedagogical reviewers. After the checklist is developed, survey is conducted by participating reviewers who are evaluating web based e-Learning content in Sri Lanka and in some other countries in the world. According to their feedbacks, we expect to develop a standardized checklist which contains most of the required reviewing factors.

Among these eleven main review factors the Evaluation or Assessment review factor was highly ranked by the pedagogical reviewers in the survey. Evaluation or Assessment is essential to the learning process in web-based education and is a recognized way of measuring effective learning and assess learner's progress. Under this main review factor, "A number of assignments or exercises are provided," "For each exercise, step by step instructions are given," "Evaluation and grading criteria is clearly mentioned," "The number of assignments and their due dates are provided," "Guidelines for participating in online discussions are given," and "Method of assessments is given" are the sub review factors considered in this main review factor. This study focused on giving comparative clarification about factors considered under Evaluation or Assessment in the manual pedagogical evaluation process of web-based e-Learning. This will help to develop a supporting tool to measure the pedagogical effectiveness of Evaluation or Assessment as a main review factor and its sub review factors.

The rest of the paper is arranged as follows. Literature Review describes a review of existing checklists used in the manual pedagogical evaluation process of web-based e-Learning. Methodology describes the way we followed when selecting the main review factors and its corresponding sub review factors. Next section gives the detail description of the calculation of the significance of the Evaluation or Assessment main review factor and its sub review factors and then gives the analysis of the feedbacks of the pedagogical reviewers Finally, discussion and conclusion of the paper with a note on further works.

\section{Review of Existing Checklists Used in the Pedagogical Evaluation Process of Web-Based E-Learning}

Based on the study of the manual pedagogical evaluation process, we encountered, Inconsistency is the biggest challenge faced by pedagogical reviewers. This is evident according to the Table 1 in the literature review section different institutes used different set of checklists in order to pedagogically evaluate their web based eLearning content.

Table 1 Review Factors of the Existing Checklists

\begin{tabular}{ll} 
Source & Review Factors \\
\hline $\begin{array}{l}\text { Developing and Reviewing Online Courses: } \\
\text { Items for Consideration (Wright, 2011) }\end{array}$ & $\begin{array}{l}\text { General Consideration, Accessibility, Organization, Language, } \\
\text { Layout, Goals and Objectives, Course Content, Instructional or } \\
\text { Learning Strategies, Learning Resources and Evaluation }\end{array}$ \\
\hline $\begin{array}{l}\text { Guide to Online Course Design and Quality } \\
\text { Standards checklist (US Department of }\end{array}$ & $\begin{array}{l}\text { Course Overview and Introduction, Learning Objectives, } \\
\text { Assessment and Measurement, Resources and Materials, Learner } \\
\text { Interaction, Course Technology, Learner Support and } \\
\text { Accessibility }\end{array}$ \\
\hline Post-Course Evaluation Checklist for the use & Accessibility, Content, Goals and objectives, Structure, Visual \\
\hline
\end{tabular}




\begin{tabular}{|c|c|}
\hline $\begin{array}{l}\text { of eLearning Developers, presented by John } \\
\text { Laskaris (Laskaris, 2015) }\end{array}$ & $\begin{array}{l}\text { design, Text, Timing, eLearning resources, Interactivity, } \\
\text { Multimedia, Assessments, eLearning professional contribution, } \\
\text { availability of social interactions, eLearning course expectations } \\
\text { and Overall eLearning experience }\end{array}$ \\
\hline $\begin{array}{l}\text { A Checklist to Assess the Quality of an E- } \\
\text { Learning Course, presented by Alison } \\
\text { Bickford (Bickford, 2013) }\end{array}$ & $\begin{array}{l}\text { Instruction, Graphic User Interface (GUI), Navigation, Visual } \\
\text { design, Instructional approach, Interactivity, Use of narration/text, } \\
\text { Assessment and Cultural fit }\end{array}$ \\
\hline $\begin{array}{l}\text { The Ultimate eLearning Course Design } \\
\text { Checklist } \\
\text { (“The Ultimate eLearning Design and } \\
\text { Development Checklist,"2012) }\end{array}$ & $\begin{array}{l}\text { Course Objectives, Assessments, Course Content Creation, } \\
\text { Graphics and Fonts, Multimedia, Accessibility, Navigation, } \\
\text { Technical Issues and Overall eLearning Course Design }\end{array}$ \\
\hline $\begin{array}{l}\text { E-Learning and Distance Education in } \\
\text { University of Alaska Fairbanks (University } \\
\text { of Alaska Fairbanks, 2012) }\end{array}$ & $\begin{array}{l}\text { Welcome, Syllabus, Course Content, Interaction and } \\
\text { Collaboration, Assessment, Learner Support }\end{array}$ \\
\hline $\begin{array}{l}\text { A Compact Instructional Design Review } \\
\text { Checklist (Pappas, 2013) }\end{array}$ & $\begin{array}{l}\text { Objective, Structure, Content, Assessment, and Technology - } \\
\text { Design }\end{array}$ \\
\hline $\begin{array}{l}\text { Instructional Design Review Checklist } \\
\text { (Jebaraj, 2010) }\end{array}$ & $\begin{array}{l}\text { Objectives, Flow and Language, Instructional Strategy, } \\
\text { Presentation, Practice-feedback, Accessibility, Points to consider } \\
\text { for Analysis and Design }\end{array}$ \\
\hline $\begin{array}{l}\text { Online Course Evaluation Guidelines } \\
\text { ("guidelines.pdf," 2016) }\end{array}$ & $\begin{array}{l}\text { Course Overview/Information and Content, Learning Objectives } \\
\text { and Learning Engagement, Learner Support and Accessibility, } \\
\text { Interaction/Presence, Feedback and Assessment }\end{array}$ \\
\hline $\begin{array}{l}\text { A tool to assist in the design and redesign of } \\
\text { online courses - Illinois Central College, } \\
\text { University of Illinois("ICC-QOCI-Version- } \\
\text { 4.4-published-05.04.17-2.pdf," 2017.) }\end{array}$ & $\begin{array}{l}\text { Instructional Design, Communication, Interaction, \& } \\
\text { Collaboration, Student Evaluation and Assessment, Accreditation } \\
\text { Compliance }\end{array}$ \\
\hline $\begin{array}{l}\text { Instructional Design Review for Quality } \\
\text { eLearning by BushraZaineb (Zaineb, 2011) }\end{array}$ & $\begin{array}{l}\text { Structure, Clarity of content, Consistency, Clarity of graphics and } \\
\text { Transition }\end{array}$ \\
\hline $\begin{array}{l}\text { The Ultimate eLearning Design and } \\
\text { Development Checklist developed by Nicole } \\
\text { Legault (Legault, 2012) }\end{array}$ & $\begin{array}{l}\text { Instructional Design, Assessments \& Tests, General Design, } \\
\text { Fonts, Testing, Accessibility, Navigation Videos \& Animation, } \\
\text { Audio \& Narration, Text Content, Graphics and Technical }\end{array}$ \\
\hline
\end{tabular}

Most of the checklists discussed in the literature review have many common review factors. Though, the names of the review factors in the existing checklist were different they referred to the same or related concepts. Most of the checklists then divide the main review factors in to sub review factors to give better explanation to pedagogical reviewers. In the development process of calibrated checklist chose the most frequently occurred review factors and their corresponding sub review factors as the first step and overlapping review factors were merged, renamed them or chose one of the existing names. After studying the existing reviewing checklists, the proposed checklist comprises eleven main review factors. When selecting the review factors, we have to consider only the reviewing factors, which can be automated. The percentage of the review factors which appeared in the existing checklist is displayed in Table 2.

Table 2 Percentage of the review factors which appear in the existing checklists

\begin{tabular}{|c|c|c|}
\hline Review Factors in our checklist & No of Occurrences in existing checklists & $\%$ \\
\hline a1: Course Overview and Introduction & 7 & 58 \\
\hline a2: Accessibility & 6 & 50 \\
\hline a3: Structure of the course & 6 & 50 \\
\hline a4: User Interface of the Course & 10 & 83 \\
\hline a5: Language & 4 & 33 \\
\hline a6: Learning Resources & 4 & 33 \\
\hline a7: Interaction and Activities & 6 & 50 \\
\hline a8: Evaluation or Assessment & 9 & 75 \\
\hline a9: Learner Support & 3 & 25 \\
\hline a10: Navigational Structure & 1 & 8 \\
\hline a11: Overall Presentation Outlook & 1 & 8 \\
\hline
\end{tabular}


According to the evidence given in the Table 1, it can be obviously observed that the lack of consistency of coverage and evaluation quantification. In particularly with respect to the decision making, there is no quantitative measure is under consideration where most cases judged with qualitative analysis (de S Sirisuriya et al., 2013a). To address this issue a calibrated checklist, which can be generally used in the pedagogical evaluation process, was developed. According to the Table 2, Evaluation or Assessment of the course appeared in nine existing checklists.

\section{Methodology}

After the checklist was developed, a pilot study was conducted with the participation of a few pedagogical reviewers in Sri Lanka and based on their feedbacks, the checklist was further refined. Once the checklist was completed, a questionnaire was designed with the eleven reviewing factors and their subsequent sub reviewing factors. The questionnaire was then distributed to several expert pedagogical reviewers who are involved in evaluating web based E-Learning content, and their responses were recorded. In this survey, the pedagogical reviewers were asked to rank the sub reviewing factors according to their importance in pedagogical evaluation process of a web based E-Learning content, using a 5-point Likert scale. In this survey, we allowed pedagogical reviewers to rank the sub review factors as Extremely Important, Very Important, Moderately Important, Not Too Important and Not Important according to their importance in the pedagogical evaluation process of webbased e-Learning content. According to the feedback given by the pedagogical reviewers, the percentage value for each sub review factor under the Evaluation or Assessment main review factor were calculated and shown in Table 3.

Table 3 Percentage Value of Importance for Evaluation or Assessment

\begin{tabular}{|l|c|c|c|c|c|}
\hline Sub Review Factor & $\begin{array}{c}\text { Extremely } \\
\text { Important }\end{array}$ & $\begin{array}{c}\text { Very } \\
\text { Important }\end{array}$ & $\begin{array}{c}\text { Moderately } \\
\text { Important }\end{array}$ & $\begin{array}{c}\text { Not Too } \\
\text { Important }\end{array}$ & $\begin{array}{c}\text { Not } \\
\text { Important }\end{array}$ \\
\hline $\begin{array}{l}\text { A number of assignments or exercises } \\
\text { are provided }\end{array}$ & $45.45 \%$ & $54.55 \%$ & 0 & 0 & 0 \\
\hline $\begin{array}{l}\text { For each exercise, step by step } \\
\text { instructions are given }\end{array}$ & $59.09 \%$ & $36.36 \%$ & 0 & $4.55 \%$ & 0 \\
\hline $\begin{array}{l}\text { Evaluation and grading criteria is clearly } \\
\text { mentioned }\end{array}$ & $63.64 \%$ & $27.27 \%$ & $9.09 \%$ & 0 & 0 \\
\hline $\begin{array}{l}\text { The number of assignments and their } \\
\text { due dates are provided }\end{array}$ & $50.00 \%$ & $40.91 \%$ & $9.09 \%$ & 0 & 0 \\
\hline $\begin{array}{l}\text { Guidelines for submitting assignments } \\
\text { are given }\end{array}$ & $54.55 \%$ & $40.91 \%$ & $4.54 \%$ & 0 & 0 \\
\hline Method of assessments is given & $50.00 \%$ & $36.36 \%$ & $13.64 \%$ & 0 & 0 \\
\hline
\end{tabular}

\section{Significance of the Evaluation or Assessment}

The contributions for the evaluation mention in eleven factors (Course Overview and Introduction, Accessibility, Structure of the Course, Learner Interface of the Course, Language, Learning Resources, Interaction and Activities, Evaluation or Assessment, Learner Support, Navigational Structure and the Overall Presentation Outlook) differ from factor to factor. It's better to having weights according to their importance in evaluation process. The contributions for the evaluation devised from the above factors, $\mathrm{a}_{1}-\mathrm{a}_{11}$, and their respective weightings, $\mathrm{w}_{1}-\mathrm{w}_{11}$, can be represented as follows,

$$
\begin{aligned}
& \mathrm{E}=\mathrm{a}_{1} \cdot \mathrm{w}_{1}+\mathrm{a}_{2} \cdot \mathrm{w}_{2}+\ldots . .+\mathrm{a}_{11} \cdot \mathrm{w}_{11} \\
& \text { where, } \mathrm{w}_{1}+\mathrm{w}_{2}+\ldots+\mathrm{w}_{11}=1
\end{aligned}
$$


Further, the values derived from each factor also depend on a number of sub reviewing factors in each main review factor. The contribution from each factor can be represented using a form of following equation (3).

$$
a_{i}=\frac{\sum_{t=0}^{n} c_{t}}{n}
$$

where, ct is a value given from a rating scale for each sub review factor under main review factor and we can extract values by submitting an actual e-Learning material. ct lies between 0 to 1 .

As mention in above pedagogical reviewers have to rank the sub reviewing factors as Extremely Important, Very Important, Moderately Important, Not Too Important and Not Important according to their importance in pedagogical evaluation process of web-based e-Learning content. Then assign the values for rank as +2 to -2 . According to the feedback given by pedagogical reviewers, we calculated the percentage value for each sub reviewing factor under each rank as $\mathrm{p} \%, \mathrm{q} \%, \mathrm{r} \%, \mathrm{~s} \%$ and $\mathrm{t} \%$. Then multiply the percentage value with the values of ranks to calculate the value of $b_{\mathrm{ij}}$. Calculate the $b_{\mathrm{ijj}}$ value for all the sub reviewing factors under each main review factor.

$$
b_{i j}=2 * p+1 * q+0 * r+(-1)^{*} \mathrm{~s}+(-2)^{*} \mathrm{t}
$$

where i goes from 1 to number of sub reviewing factors in each eleven main review factors.

When $b_{i j}$ gets a minus value that means the particular sub reviewing factor has not important in pedagogical evaluation process of web-based e-Learning content. Then we are not considering that factor for future implementation. Then calculate the summation of all positive $b_{i j}$ values and divide it by number of sub reviewing factors and assign it to parameter $\mathrm{R}$.

$$
R_{i}=\frac{\sum b_{i j}}{m}
$$

Then we divide $\mathrm{R}$ by 2 because we can get maximum value 2 for ranks.

$$
x_{i}=\frac{R_{i}}{2}
$$

Then add all values given for above mention eleven factors.

$$
T=\sum_{i=0}^{11} x_{i}
$$

Finally, the importance of each of the eleven review factors was calculated.

$$
w_{i}=\frac{x_{i}}{T}
$$

where i goes from one to eleven main reviewing factors.

According to the above equation (1), the evaluation can be rated based on the rating scale depth. The prime target of getting feedback on devised tool is to emphatically obtain the more logic values for the above weights. For each sub reviewing factor under "Evaluation or Assessment" main review factor, the calculation is performed using the equation (4) to obtain values for $b_{i j}$ by multiplying the percentage value by the values of the respective ranks as presented in Table 4. 
Table $4 b_{i j}$ values of the relevant Sub Review Factors of the Evaluation or Assessment main review factor

\begin{tabular}{|l|c|c|}
\hline Sub Review Factor & $\mathrm{b}_{\mathrm{ij}}$ & 1.45 \\
\hline $\begin{array}{l}\text { A number of assignments or exercises } \\
\text { are provided }\end{array}$ & $45.45 \% * 2+54.55 \% * 1=1.4545$ & 1.50 \\
\hline $\begin{array}{l}\text { For each exercise, step by step } \\
\text { instructions are given }\end{array}$ & $59.09 \% * 2+36.36 \% * 1+4.55 \% *(-1)=1.4999$ & 1.54 \\
\hline $\begin{array}{l}\text { Evaluation and grading criteria is clearly } \\
\text { mentioned }\end{array}$ & $63.64 \% * 2+27.27 \% * 1+9.09 \% * 0=1.5455$ & 1.40 \\
\hline $\begin{array}{l}\text { The number of assignments and their } \\
\text { due dates are provided }\end{array}$ & $50.00 \% * 2+40.91 \% * 1+9.09 \% * 0=1.4091$ & 1.50 \\
\hline $\begin{array}{l}\text { Guidelines for submitting assignments } \\
\text { are given }\end{array}$ & $54.55 \% * 2+40.91 \% * 1+4.54 \% * 0=1.5001$ & 1.36 \\
\hline Method of assessments is given & $50.00 \% * 2+36.36 \% * 1+13.64 \% * 0=1.3636$ & \\
\hline
\end{tabular}

Analysis of the feedbacks of Pedagogical Reviewers

"Evaluation or Assessment" is identified as important factor in pedagogical evaluation process of web based eLearning content. Evaluation or Assessment strategies provide systematic ways to measure effective learning and assess student progress in relation to learning objectives (Kearns, 2012). Under this review factor, "Evaluation and grading criteria is clearly mentioned" sub review factor is highly ranked by pedagogical reviewers. "For each exercise, step by step instructions are given" and "Guidelines for submitting assignments are given" are the next sub review factors that received high scores from the pedagogical reviewers., "A number of assignments or exercises are provided" and "The number of assignments and their due dates are provided" are the two reviewing factors which received third and fourth highest scores from the reviewers in the survey. "A number of assignments or exercises are provided" is in line with the Assess Performance in Gange's Nine Events of Instructions (Kruse, 2010). "Method of assessments is given" was received lowest score from the reviewers. Under Method of assessments, sub factor, Self-check or practice types of assignments and interactive games have in built feedback and instructor participation in discussion of assignments are used to give frequent and meaningful feedback to students and help them to learn more effectively.

\section{Discussion and Conclusion}

Based on the survey findings "Evaluation or Assessment" is considered as important in the pedagogical evaluation process of web-based e-Learning. A calibrated checklist designed in this study contains the most required reviewing factors that offer solution to overcome inconsistency that may occur in the manual evaluation process. A quantitative formula were also devised to calculate the importance of each review factor along with their related sub review factors, and produce the output in the form of values that weight the importance of each factors. The calculated values of importance can be used to provide instructional designers with quantitative feedbacks during the pedagogical evaluation process of web-based e-Learning content. The feedback with quantitative measurement is more beneficial to the instructional designer rather than having qualitative judgment. Based on the findings a supporting tool is going to develop to measure the pedagogical effectiveness of "Evaluation or Assessment" as a main review factor and its sub review factors of the given eLearning content as further works. The develop supporting tool is needed to integrate the design and development of a computerized tool for assisting pedagogical reviewers in their evaluation process. The proposed computerized tool can speed up the evaluation and provide quick feedback to instructional designers. This helps the instructional designer to develop high quality e-Learning content that will improve the value of an e-Learning website. As a result, the learner would be benefited from a well-designed e-Learning content, and thus improve his/her learning motivation and intellectual commitment to follow e-Learning courses. 


\section{References}

Bickford, A., 2013. ELearning_quality_checklist_ConnectThinking2013.pdf [WWW Document]. URL http://www.elearningacademy.com.au/wpcontent/uploads/2013/05/ELearning_quality_checklist_ConnectThinking2013.pdf (accessed 9.23.16).

de S Sirisuriya, S.C.M., Ranathunga, L., Karunanayaka, S.P., Abdullah, N.., 2013a. Calibration checklist to use in an automated pedagogical evaluation process of web based E-Learning, in: 2013 8th IEEE International Conference on Industrial and Information Systems (ICIIS). Presented at the 2013 8th IEEE International Conference on Industrial and Information Systems (ICIIS), pp. 162-167. https://doi.org/10.1109/ICIInfS.2013.6731974

de S Sirisuriya, S.C.M., Ranathunga, L., Karunanayaka, S.P., Abdullah, N.., 2013b. Can pedagogical evaluation process of web based E-Learning be automated?, in: 2013 8th International Conference on Computer Science Education (ICCSE). Presented at the 2013 8th International Conference on Computer Science Education (ICCSE), pp. 650-655. https://doi.org/10.1109/ICCSE.2013.6553989

guidelines.pdf, n.d.

ICC-QOCI-Version-4.4-published-05.04.17-2.pdf, n.d.

Jebaraj, A., 2010. Instructional Design(ID) Review Checklist.

Kearns, L.R., 2012. Student Assessment in Online Learning: Challenges and Effective Practices 8, 11.

Laskaris, J., 2015. 15-point Post-Course Evaluation Checklist for eLearning Developers [WWW Document]. eFront Blog. URL https://www.efrontlearning.com/blog/2015/07/15-point-post-course-evaluation-checklist-forelearning-developers.html (accessed 4.27.18).

Legault, N., 2012. The Ultimate eLearning Design and Development Checklist - Flirting w/ eLearning [WWW Document]. URL https://nlegault.ca/2012/03/18/the-ultimate-e-learning-design-and-development-checklist/ (accessed 3.31.16).

Pappas, C., 2013. A Compact Instructional Design Review Checklist [WWW Document]. eLearning Industry. URL https://elearningindustry.com/a-compact-instructional-design-review-checklist (accessed 9.23.16).

The Ultimate eLearning Design and Development Checklist, 2012. . Flirting w/ eLearning.

University of Alaska Fairbanks, 2012. CourseChecklist-Jun12-nolines - Course_Review_Checklist.pdf [WWW Document]. URL https://elearning.uaf.edu/wpcontent/uploads/2011/06/Course_Review_Checklist.pdf?utm_campaign=elearningindustry.com\&utm_source= \%2Fa-compact-instructional-design-review-checklist\&utm_medium=link (accessed 9.23.16).

US Department of Education, 2006. GUIDE TO ONLINE COURSE DESIGN AND QUALITY STANDARDS. Wright, C.R., 2011. Developing and Reviewing Online Courses: Items for Consideration 16.

Zaineb, B., 2011. Instructional Design Review for Quality eLearning. Custom Training and E-learning, Anywhere Anytime! 